Indian Journal of Clinical Biochemistry, 1998, 13(2), 55-62

INTERFERENCES IN CLINICAL CHEMISTRY ANALYSIS

\author{
K. S. S. Saibaba, M. Vijaya Bhaskar\#, P.V.L.N. Srinivasa Rao, G.V. Ramana and \\ K.V. Dakshinamurty*
}

Department of Biochemistry, Sri Venkateswara Institute of Medical Sciences (SVIMS), \#S.V. Medical College, Tirupati - 517507, 'Department of Nephrology, Nizam's Institute of Medical Sciences, Hyderabad, Andhra Pradesh.

\begin{abstract}
Analyses of body fluids in clinical chemistry laboratory are subject to a number of interferences that affect the analytical accuracy. The interferents arise from exogenous sources like drugs and additives as well as such endogenous sources like lipemia, hemolysis and icteria. Our studies demonstrate matrix interference in the form of analytical bias between serum and aqueous matrix calibrators. The clinical chemist should constantly be aware of this factor. Correction of interferences is recommended as an integral part of the quality assurance program.
\end{abstract}

KEW WORDS: Interference, Bichromatic analysis, Matrix effects, Hemolysis, Quality assurance.

All of us are well versed with the physics behind eclipses. As long as there is nothing in between, sunlight bathes the earth forming the basis for life. And whenever moon blocks the path, Sun is not visible. Thus interference by moon causes solar eclipse resulting in darkness.

Similarly in clinical chemistry laboratory, this problem of interference forms an important source of analytical errors and affects the analysis of blood and other body fluids, thus being detrimental to patient-care. Further, it may also be observed with (internal and external) quality control materials. Interferents may produce a positive or negative bias in the result. Since the goal of the Biochemistry laboratory is to report accurately and precisely, it is imperative that all clinical chemists aim to eliminate or minimise such analytical errors along with the pre and post analytical errors $(1,2)$ as a part of the Quality Control Program (3).

Author for correspondence

Dr. K.S.S. Saibaba

Associate Professor at above address.
This mini-review attempts to cover the interferences encountered in clinical chemistry analyses based on absorption spectrophotometry. The general concepts are discussed that help to control and minimize the effects of interferents on method accuracy and precision.

\section{DEFINITION AND CLASSIFICATION}

Interference is defined as "the effect of a substance present in the sample that alters the correct value of the result for an analyte" (4).

Depending on the source of the interferent, interference may be classified as exogenous or endogenous.

\section{A. Exogenous interferents}

These are again categorized into drugs, additives and matrix effects. 
Drugs: The significance of drug interference on laboratory analysis may be appreciated from the results (table 1) of a survey (5) conducted to assess this problem.

Drugs, being biologically active, are reactive with reagents or analytes. Metabolites of drugs also cause interference, sometimes being more reactive than the parent compound. Furosemide by itself does not interfere with the Jaffe method for creatinine, but given in high doses leads to the formation of a metabolite that causes a negative interference (6). Cephalothin and cefoxitin cause a positive interference with the Jaffe method for creatinine (7). Phenytoin and its major metabolite, 5-(p-hydroxyphenyl)-5- phenylhydantoin, create false-positive reactions in a method for barbiturates (8). Ascorbic acid causes a negative interference with glucose oxidase method for glucose (9). A list of the known effects of drugs on chemical analysis was developed and published by Donald Young and it remains the best and only single listing of drug effects on laboratory tests (10).

As the number of drugs available to physicians is increasing day by day, the problem of drug interference on laboratory analysis is also on the rise. Understanding the mechanism of drug interference requires knowledge of the chemistry of the drug and its metabolites. Clinical chemists have to use an alternate method based on a principle different from the original one to detect these interfererices.

Additives: Materials added as anticoagulants can interfere with the analysis of many analytes. For example, fluoride interferes with many enzymatic methods.

Matrix effects: These are defined as "a bias or difference caused by a sample property other than the level of the substance or property that is intended to be measured. It includes physiochemical, mechanistic, and analytical interferences and substarice isoforms"(11). The contribution of matrix effects to analytical inaccuracy is gaining such an importance that the College of American Pathologists had conducted a conference on "Matrix effects and accuracy assessment in clinical chemistry".

Ross et. al., in an extensive study involving
977 laboratories, reported evidence of bias due to matrix effects in $70 \%$ of 37 instrument/reagent specific systems (12). Matrix effects can also cause nonlinearity in biochemical analysis. Recently we have reported the interference caused by matrix effects by analysing fresh serum specimens using calibration with serum matrix calibrator as well as aqueous matrix calibrator (13). Despite good correlation, there was statistically significant bias between the two calibrations for most of the analytes. A proportional systematic error was found pointing to a calibration disparity between the two types of calibrators. These findings suggest an analytical bias between serum and aqueous matrix calibrations that could result in a lack of commutability among various laboratories.

\section{B. Endogenous interferents}

The major sources of endogenous interferents are lipemia, hemolysis, bilirubinemia and paraproteinemia.

Lipemia: Circulating lipid particles, namely VLDL and chylomicrons, cause turbidity due to light scattering (interaction of light with particles that bend the light away from its original path) and volume displacement. Light scattering effect of lipemia may interfere with the analy'ses of glucose. bilirubin, total protein, phosphorus and uric acid (Fig. 1A). Light scatter can also profoundly affect nephelometry. Volume displacement may produce pseudo-hyponatremic values.

Hemolysis: In vitro hemolysis (breakage of red blood cells giving the sample red color) occurs at the time of specimen collection or transport. Factors which may lead to hemolysis include venostasis, excessive aspiration, mixing or force during ejection of blood, prolonged standing of the whole blood, contamination with detergents or water, excessive cooling or heating and extremely fast centrifugation. Hemolysis can be discerned with the naked eye at serum hemoglobin concentrations of $0.02 \mathrm{~g} / \mathrm{dL}$ and above. Icteric serum has the potential to hide even greater concentrations of hemoglobin.

Interference by hemolysis can be classified into 3 different types:

1. Hemoglobin may interfere as a result of its 
intrinsic color alone. The degree of this interference depends on the wavelength used, as evident from the figure (Fig. 2A and 2B).

2. Hemoglobin and other substances released on hemolysis may affect specific chemical reactions. For e.g., hemoglobin interferes with the diazotization of bilirubin; it also inhibits serum lipase activity by $50 \%$ at a concentration of $0.5 \mathrm{~g} / \mathrm{dL}$ (14). Adenlylate kinase released during hemolysis interferes with the determination of creatine kinase (CK) activity.

3. On hemolysis, the cellular components of RBCs i.e., lactate dehydrogenase (LDH), potassium, magnesium are released. Given that the intracellular concentration of $L D H$ is 160-fold greater, potassium 22-fold greater, and magnesium 3-fold greater than in plasma, they invariably result in falsely elevated values.

Bilinubin: As for hemolysis, interference from bilirubin may arise from different mechanisms:

1. Bilirubin may interfere with clinical chemistry analysis by its ability to react chemically with reagents. Bilirubin causes a negative interference with creatinine estimation; it also

\section{A. LIPEMIA INTERFERENCE}

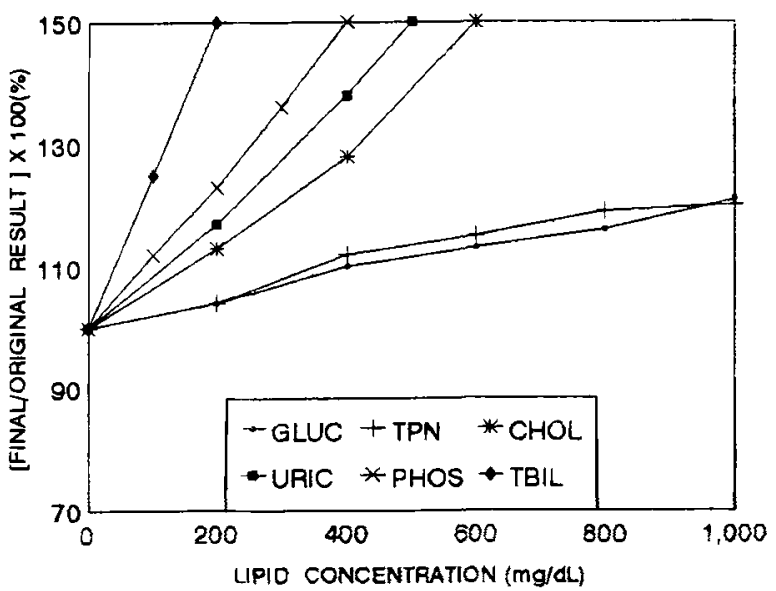

interferes with peroxidase-coupled reactions as are used in the determinations of glucose, cholesterol, triglycerides and uric acid. ( Fig. 1B).

2. Bilirubin may cause interference because of its spectral properties related to the strong absorbance of bilirubin between 400 and 540 $\mathrm{nm}$.

Paraproteinemia: Paraproteins circulate as the result of diseases like multiple myeloma. These proteins may increase the viscosity of serum making proper volume sampling difficult. IgG may complex with CK-BB and form macro-CK 1 , which has a longer circulating half-life than $C K$ giving a spuriously elevated activity (15). Immunoglobulins can also form macro complexes with $\mathrm{LDH}$ and amylase.

\section{CORRECTION OF INTERFERENCES}

The correction of interference depends on its nature i.e., whether it is caused by competing chemical reactions or is of a spectral nature.

\section{CORRECTION OF CHEMICAL INTERFERENCES}

This can be achieved by the following techniques:

\section{B. BILIRUBIN INTERFERENCE}

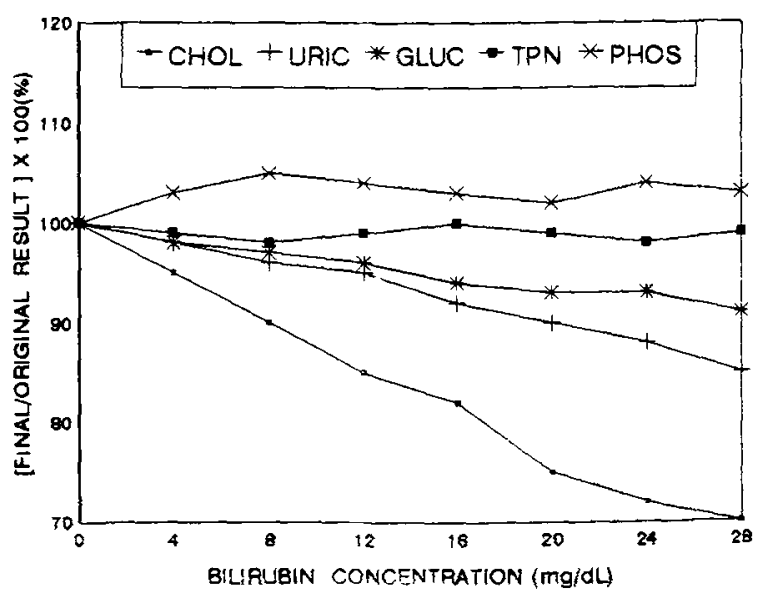

Fig.1. Effect of (A) Lipemia and (B) Icteria on clinical chemistry investigations. 
2A

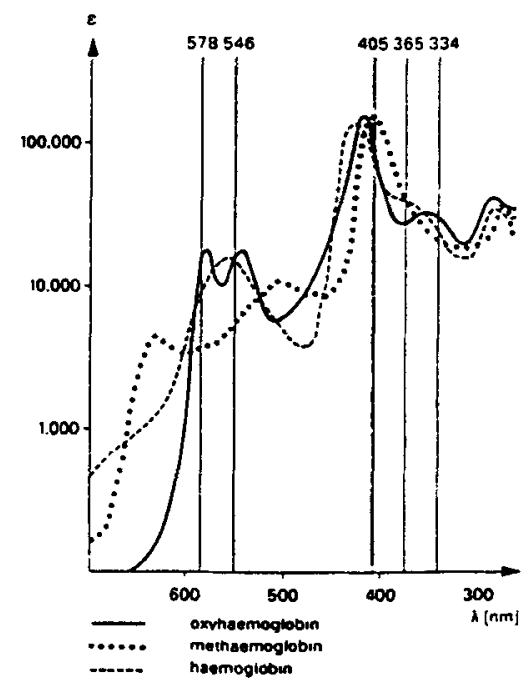

2B. HEMOGLOBIN INTERFERENCE

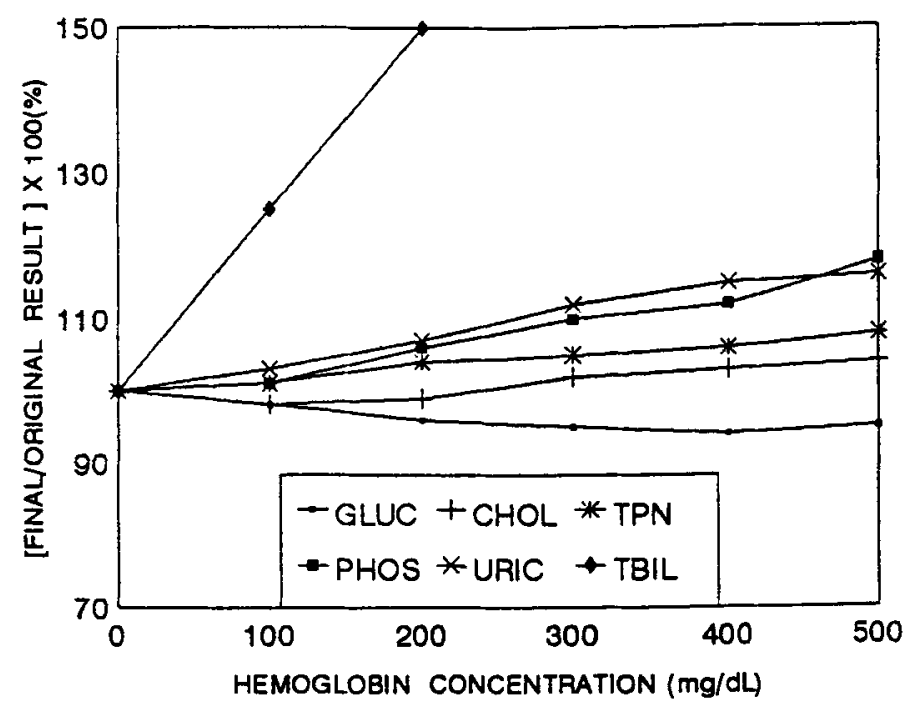

Fig.2. A. Absorption spectra of hemogiobin derivatives and B. Hemoglobin interference on clinical chemistry investigations

1. Removal of the interferent: This may be accomplished by using (a) a protein-free sample, (b) absorption, or (c) liquid-liquid extraction.

2. Dilution: This is effective in the case of interferents that do not produce the same color intensity or react at the same rate as the analyte we are measuring.

3. Using a more specific chemical reaction: Examples of this approach include the use of specific enzymes as reagents for the measurement of glucose (hexokinase or glucose oxidase), urea (urease), cholesterol (cholesterol oxidase), and uric acid (uricase). Immunossays also fall in this category of improving specificity to counter interference.

4. Two-point kinetic measurement: This approach is based on the observation that many interferents react at a diffierent rate than the specific analyte of our interest does. By properly choosing an optimal window (the term denotes a specific time during which reactions are monitored) of time for the two absorbance readings for the kinetic analysis, we can minimize the interference of the fastreacting and slow-reacting interferents, and measure the absorbance change caused primarily by the analyte of interest. This principle is used for the estimation of creatinine by Jaffe Kinetic method.

\section{CORRECTION OF SPECTRAL INTERFERENCES}

Spectral interferences are minimized by the following four techniques.

1. Sample blank: The absorbance of the assay is measured against a sample blank consisting of the sample and diluent (instead of the active reagent). Any significant color inherent to the sample is eliminated by this method. Similarly one can use reagent blank to correct for high absorbance of the reagent.

2. Bichromatic analysis: This approach is based on the idea that the absorbance maxima of the interferent will differ from that of the actual analytical reaction. The absorbance of the reaction mixture is measured simultaneously at two different wavelengths, known as the primary $\left(\lambda_{1}\right)$ and secondary $\left(\lambda_{2}\right)$ wavelengths to correct for background color. Although the measured absorbance at $\lambda_{1}\left(A_{1}\right)$ will be caused by both the analytical reaction and the interferent, the absorbance at $\lambda_{2}\left(A_{2}\right)$ will be caused by only the interferent. Standard curves are then based on either $A_{1}-A_{2}$ or $A_{1} / A_{2}$. 
3. Kinetic analysis: The absorbance of a reaction is measured at two different time points. The initial reading is taken when almost no color has formed, thereby giving the absorbance caused by endogenous spectral interferents. The second reading, taken a short time later, includes both the original endogenous color and the color formed by the analytical reaction. Thus the calculated delta absorbance $(\Delta A)$ is caused only by the specific analytical reaction. A separate sample blank measurement need not be made. This is an important technique used in autoanalysers.

4. Dilution: Dilution can sometimes reduce spectral interference, provided care is taken not to over dilute the desired analyte.

\section{LIMITATIONS OF DETECTORS}

While discussing the subject of interference in clinical chemistry analyses, it is appropriate to briefly consider the interferences that arise from limitations of detectors. The clinical chemistry laboratory measures most of the analytes by employing a detector, the spectrophotometer. There are two interrelated types of error in spectrophotometric quantitation. The first is related to the limitations of the instrument, and the second to the nature of the mathematical relationship between absorbance and percent transmission.

A. Instrument limitations: These arise from the inherent mechanism of spectrophotometry. At zero absorbance, the photo detector receives most of the light signal; any change in absorbance will be detected as a change in the percentage of this large amount of light reaching the detector. On the other hand, if the absorbance is 2.0 , only $1 \%$ of the light reaches the photo detector. The same amount of change in absorbance (as considered at zero absorbance) will be reflected as large percentage of change in the light signal. To offset this problem, the sensitivity of instrument must be very high.

Thus when measuring relatively high levels of analyte or interferent there will be a large spectrophotometric error, especially with instruments of low sensitivity. To minimize this error, a sample blank and/or a sample dilution may be employed.
B. Relationship between absorbance and transmittance: In spectrophotometry, the concentration of the chromogen and the absorbance are directly proportionate to each other. However, absorbance is only a calculated value and is logarithmically related to the percentage of transmittance $(T)$, which is the quantity actually measured. As a result, at both ends of the scale, i.e., 0.0 absorbance and high absorbance, small changes of percent $T$ will result in disproportionately large changes in the calculated absorbance leading to increased error of analysis (Table 2).

In order to minimize this type of error, one must ensure that the measurements are made at absorbance between 0.1 and 1.1 whenever possible.

Table 1. Effect of drugs on clinical chemistry investigations

\begin{tabular}{cr}
\hline $\begin{array}{c}\text { No. of drugs taken } \\
\text { by the patient }\end{array}$ & $\begin{array}{c}\text { Percentage of tests } \\
\text { affected }\end{array}$ \\
\hline 1 & $7.0 \%$ \\
2 & $16.7 \%$ \\
3 or 4 & $66.7 \%$ \\
5 or more & $100.0 \%$ \\
\hline
\end{tabular}

Table 2. Absorbance error as a function of percent $T$

\begin{tabular}{rccc}
\hline$\% T$ & Absorbance & $\begin{array}{c}\text { Variation in } \\
\text { absorbance }\end{array}$ & $\begin{array}{c}\text { Percent error } \\
\text { of absorbance } \\
\text { measurement }\end{array}$ \\
\hline $4 \pm 1$ & 1.398 & 0.22 & 15.80 \\
$10 \pm 1$ & 1.000 & 0.041 & 8.60 \\
$25 \pm 1$ & 0.602 & 0.035 & 5.79 \\
$35 \pm 1$ & 0.456 & 0.025 & 5.44 \\
$50 \pm 1$ & 0.301 & 0.017 & 5.78 \\
$70 \pm 1$ & 0.155 & 0.012 & 8.03 \\
$90 \pm 1$ & 0.046 & 0.0097 & 21.20 \\
\hline
\end{tabular}

Source: Ref. 16. 
Various commonly used drugs cause either increased values/false positives or decreased values/false negatives (Table 3 ).

Table 3. Drugs affecting laboratory test values

\begin{tabular}{|c|c|c|}
\hline $\begin{array}{l}\text { Analyte } \\
\text { Determined }\end{array}$ & $\begin{array}{l}\text { Drugs Causing Increased } \\
\text { Values or False Positives }\end{array}$ & $\begin{array}{l}\text { Drugs Causing Decreased } \\
\text { Values or False Negatives }\end{array}$ \\
\hline Acid phosphatase & Clofibrate & Alcohol, Heparin, Oxalates \\
\hline Albumin & Heparin, Phenazopyridine & $\begin{array}{l}\text { Ascorbic acid, Penicillin, Salicylic acid, } \\
\text { Sulfonamides }\end{array}$ \\
\hline Alakline phosphatase & $\begin{array}{l}\text { Allopurinol, Azathioprine, Carbamazepine, } \\
\text { Cephaloridine, Chlorpropamide, } \\
\text { Clindamycin, Erythromycin, } \\
\text { Estrogens, Imipramine, Isoniazid, } \\
\text { Methyldopa, Nitrofurantoin, Novobiocin, } \\
\text { Phenothiazines, Rifampin, Sulfonamides, } \\
\text { Tetracycline, Tolbutamide }\end{array}$ & $\begin{array}{l}\text { Oxalates, Phosphate, Propranolol, } \\
\text { Vitamin D }\end{array}$ \\
\hline Amylase & $\begin{array}{l}\text { PAS, Corticosteroids, Cyproheptadine } \\
\text { Furosemide, Histamine, Indomethacin, } \\
\text { Isoniazid, Pentazocine, Phenylbutazone, } \\
\text { Salicylates, Tetracycline, Thiazide diuretics }\end{array}$ & Citrates, Ethacrynic acid, Oxalates \\
\hline Bilirubin & $\begin{array}{l}\text { Acetazolamide, Allopurinol, PAS, } \\
\text { Amphotericine B, Anabolic steroids, } \\
\text { Ascorbic acid, Azathioprine, } \\
\text { Carbamazepine, Chloroquine, } \\
\text { Chlorpropamide, Clindamycin, Diazepam, } \\
\text { Erythromycin, Ethambutol, Flourazepam, } \\
\text { Gentamicin, Imipramine, Indomethacin, } \\
\text { Isoniazid, Levodopa, Menadione, Mercaptopurine, } \\
\text { Methotrexate, Nitrofurans, Novobiocin, Primaquine, } \\
\text { Propylthiouracil, Pyrazinamide, Sulfonamides, } \\
\text { Tetracyclines, Tolbutamide }\end{array}$ & $\begin{array}{l}\text { Barbiturates, Caffeine, Citrate, Protein, } \\
\text { Salicylates (large amounts), } \\
\text { Sodium chloride, Penicillin, Urea }\end{array}$ \\
\hline BUN & $\begin{array}{l}\text { Acetone, Alkaline antacids, PAS, } \\
\text { Amphotericin B, Ascorbic acid, Bacitracin, } \\
\text { Ethacrynic acid, Furosemide, Gentamicin, } \\
\text { Hydantoins, Indomethacin, Kanamycin, } \\
\text { Methicillin, Methyldopa, Mithramycin, Nalidixic } \\
\text { acid, Nitrofurantoin, Polymyxin B, Propranolol, } \\
\text { Salicylates, Sulfonamides, Tetracyclines, } \\
\text { Thiazide diuretics, Vancomycin }\end{array}$ & $\begin{array}{l}\text { Chloramphenicol, Dextrose infusions, } \\
\text { Phenothiazines }\end{array}$ \\
\hline Calcium & $\begin{array}{l}\text { Alkaline antacids, Estrogens, Potassium, } \\
\text { Progestins, Sodium, Thiazide diuretics, } \\
\text { Urea, Vitamin D }\end{array}$ & $\begin{array}{l}\text { Acetazolamide, Aspirin, Corticosteroids, } \\
\text { Gentamicin, Heparin, Insulin, Methicillin, } \\
\text { Oxalate, Sulfadiazine }\end{array}$ \\
\hline Cholesterol & $\begin{array}{l}\text { Aminopyrine, Anabolic agents, Aspirin, } \\
\text { Chlorpromazine, Clofibrate, lodides, } \\
\text { Penicillamine, Phenothiazines, Salicylates, } \\
\text { Thiouracil, Urea }\end{array}$ & $\begin{array}{l}\text { PAS, Ascorbic acid, Bile salts, Chlortetra- } \\
\text { cycline, Colchicine, Estrogens, Glucose, } \\
\text { Heparin, Kanamycin, Nicotinic acid, } \\
\text { Phenformin }\end{array}$ \\
\hline Creatinine & $\begin{array}{l}\text { Albumin, Amphotericin B, Ascorbic acid, } \\
\text { Barbiturates, Clofibrate, Colistin, Glucose, } \\
\text { Kanamycin, Levodopa, Mannitol, Methicillin }\end{array}$ & Viomycin \\
\hline
\end{tabular}


Glucose (fasting)

Phosphate

Potassium

Protein total

SGOT

SGPT

Sodium

Uric acid
Acetaminophen, Acetazolamide, PAS

Caffeine, Diphenylhydantoin, Estrogens,

Furosemide, Imipramine, Nalidixic acid, Nitrofurantoin, Tetracycline, Thiabendazole

Methicillin, Totracyclines

Amiloride, Calcium, Cephaloridine, Copper, Iron, Isoniazid, Mannitol, Methicillin

Tetracyclines

Bilirubin, Clofibrate, Lipemia, Tolbutamide

Ampicillin, Ascorbic acid, Cephalothin, Chloroquine, Clindamycin, Cloxacillin,

Diphenylhydantoin, Erythromycin, Ethambutol,

Gentamicin, Indomethacin, Isoniazid, Methotrexate,

Nalidixic acid, Nitrofurantoin, Propranolol,

Suffamethazole, Tetracycline, Tolbutamide.

Cardiotonic glycosides, Clindamycin, Codeine,

Desipramine, Erythromycin, Ethionamide,

Flurazepam, Gentamicin, Indomethacin.

Isoniazid, Methyldopa, Morphine, Phenothiazines,

Propranolol, Pyrazinamide, Tetracycline

Calcium, Copper, Iron, Methyldopa, Protein

Acetazolamide, Acetaminophen, Aminophylline, Ampicilin, Ascorbic acid, Aspirin, Coffee, Ethambutol, Gentamicin, Levodopa,

Mercaptopurine, Methicillin, Methotrexate,

Penicillin, Pyrazinamide, Spiranolactone
Anabolic steroids, Clofibrate, Cyproheptadine, Guanethidine, Isoniazid, MAO inhibitors,

Nitrazepam, Propranolol, Reserpine

Insulin, Phenothiazine, Promethazine

Acetazolamide, Amphotericin B, Carbanexolone, Furosemide, Polymyxin B, Salicylates,

Dextran, Pyrazinamide, Salicylates
Dichlorphenamide, Furosemide, Heparin

Acetohexamide, Allopurinol, Anticoagulants, Mannitol, Phynylbutazone

Source: Ref. 17

\section{REFERENCES}

1. Narayanan, S. (1996) Pre and post analytical errors. Ind. J. Clin. Biochem. 11 (1), 7-11

2. Narayanan, S. (1996) Pre and post analytical errors in lipid determination. Ind. J. Clin. Biochem. $11(1), 12-16$.

3. Kanagasabapathy, A.S., Swaminathan, S. and Selvakumar, R. (1996). Quality control in clinical biochemistry. Ind. J. Clin. Biochem. 11 (1) 17-25.

4. Kroll, M.H. and Elin, R. J. (1994) Interference with Clinical Laboratory Analyses. Clin. Chem. 40 (11), 1996-2005.

5. Munzenberger, P. and Emmanuel, S. (1971). The incidence of drug diagnostic test interferences in outpatients Am. J. Hosp. Pharm. 28 786-91.

6. Murphy, J.L., Hurt, T.L., Griswold, W.R., Peterson, B.M., Rodrate, A. and Krouse, H.F. (1989) Interference with creatinine concentration measurement by high dose furosemide infusion. Crit. Care Med. 17, 889-890

7. Saah, A.J., Koch T.R. and Drusano, G.L. (1982) Cefoxitin falsely elevates creatinine levels. J. Am. Med. Assoc. 247, 205-206.

8. Siff K.S. and Finkler, A.E. (1988) False positive barbiturate test in urine owing to phenytoin and 5-(p- hydroxyphenyl) -5-phenylhydantoin (Tech Brief) Clin. Chem. 34, 1359-1360. 
9. Siest, G., Dawkins, S.J. and Galteau, M.M. (1983) Drug effects on laboratory tests. J. Pharm. Biomed. Anal. 1, 247-257.

10. Young, D.S., Pestaner, L.C. and Gibberman, V. (1975) Effect of drugs on clinical laboratory tests. Clin. Chem. 21, 1D-432 D.

11. Lasky, F.D. (1993) Achieving accuracy for routine clinical chemistry methods. Arch. Pathol. Lab. Med. 117, 412-419.

12. Ross, J.W., Myers, G.L., Gilmore, B.F., Cooper, G.R., Naito, H.R. and Eckfeldt, J. (1993) Matrix effects and the accuracy of cholesterol analysis. Arch. Pathol. Lab. Med. 117, 393-400.

13. Saibaba, K.S.S., Srinivasa Rao, P.V.L.N., Ramana, G.V., Kumar. E.G.T.V., and Tripathi, R.L. (1995) Analytical bias due to calibrator matrix effects. Ind. J. Clin. Biochem. 10 (2), 112-115.

14. Henry R.J., Sobel, C. and Berkman, S. (1957) On the determination of "pancreatic lipase" in serum. Clin. Chem. 3, 77-89.

15. Pudek, M.R. and Nanji, A.A. (1983) Antibody interference with biochemical tests and its clinical significance. Clin. Biochem. 16, 275-80

16. Kaplan, L.A. and Pesce, A.J. (1989) Interferences in chemical analysis In: Clinical Chemistry Theory, analysis and correlation. Eds. Kaplan L.A. and Pesce, A.J. The C.V. Mosby Company. St. Louis, USA, 2nd edn. p.808-819.

17. Fischbach, F.T. (1984) A manual of laboratory diagnostic tests. J.B. Lippincot Company, Philadelphia, 2nd edn. p. 823-847. 